\title{
Peripheral sympathetic mechanisms in orofacial pain
}

This article was published in the following Dove Press journal: Journal of Pain Research

\author{
Wenguo Fan ${ }^{1,2}$ \\ Xiao Zhu ${ }^{3}$ \\ Yifan $\mathrm{He}^{1}$ \\ Hongmei $\mathrm{Li}^{4}$ \\ Wenzhen $\mathrm{Gu}^{\prime}$ \\ Fang Huang' \\ Hongwen $\mathrm{He}^{\prime}$ \\ 'Institute of Stomatological Research, \\ Sun Yat-sen University, Guangdong \\ Provincial Key Laboratory of \\ Stomatology, Guangzhou, China; \\ ${ }^{2}$ Department of Anesthesiology, \\ Guanghua School of Stomatology, \\ Hospital of Stomatology, Sun Yat- \\ sen University, Guangzhou, China; \\ ${ }^{3}$ The Public Service Platform of \\ South China Sea for R\&D Marine \\ Biomedicine Resources, Marine \\ Biomedical Research Institute, \\ Guangdong Medical University, \\ Zhanjiang, China; ${ }^{4}$ Department \\ of Pathology, Guangdong Medical \\ University, Dongguan, China
}

\begin{abstract}
Sympathetic nervous system (SNS) is a part of the autonomic nervous system which involuntarily regulates internal body functions. It appears to modulate the processing of nociceptive information. Many orofacial pain conditions involve inflammation of orofacial tissues and/or injury of nerve, some of which might be attributed to SNS. Thus, the aim of this review was to bring together the data available regarding the peripheral sympathetic mechanisms involved in orofacial pain. A clearer understanding of SNS-sensory interactions in orofacial pain may provide a basis for novel therapeutic strategies for conditions that respond poorly to conventional treatments.
\end{abstract}

Keywords: sympathetic nervous system, norepinephrine, adrenergic receptors, orofacial pain

\section{Introduction}

Sympathetic nervous system (SNS) arises from the spinal cord between the first thoracic vertebra and the second lumbar vertebra and travels to sympathetic ganglia, where it synapses with a postganglionic neuron. From there, the long postganglionic neurons extend across most of the body. The SNS, as a component of the autonomic nervous system, reaches most of the body's internal organs to maintain homeostasis together with the para-SNS. ${ }^{1}$ The American Academy of Orofacial Pain (AAOP) defined the term "orofacial pain" as "pain conditions that are associated with the hard and soft tissues of the head, face, neck, and all the intraoral structures." Orofacial pain sensation from the intraoral and extraoral structures of the head and face is relayed to the central nervous system (CNS) by trigeminal nerve system. Primary sensory fibers innervating the orofacial region derive from neurons of the trigeminal ganglion (TG). The central processes of TG enter directly into the pons, where they descend in the brainstem to synapse in the spinal trigeminal nucleus (STN). ${ }^{3,4}$ The secondary afferents from STN cross to the opposite side and project to higher center (Figure 1). SNS (visceral motor nerve) and the sensory nerves are generally regarded as discrete structures, but the efferent SNS and the afferent nociceptive interact in many ways. Activation of SNS can suppress or augment pain in pathological states, which might take place in the periphery or the CNS..$^{5-7}$ Considerable evidence has demonstrated that SNS might regulate peripheral sensitized nociceptors, immune cells, and neuroactive molecules, which are potentially relevant for the pathophysiology of orofacial pain. The purpose of this study was to present different lines of evidence for the role of SNS in orofacial pain studied to date. Possible peripheral mechanisms regarding the connection between SNS and orofacial pain are discussed. 


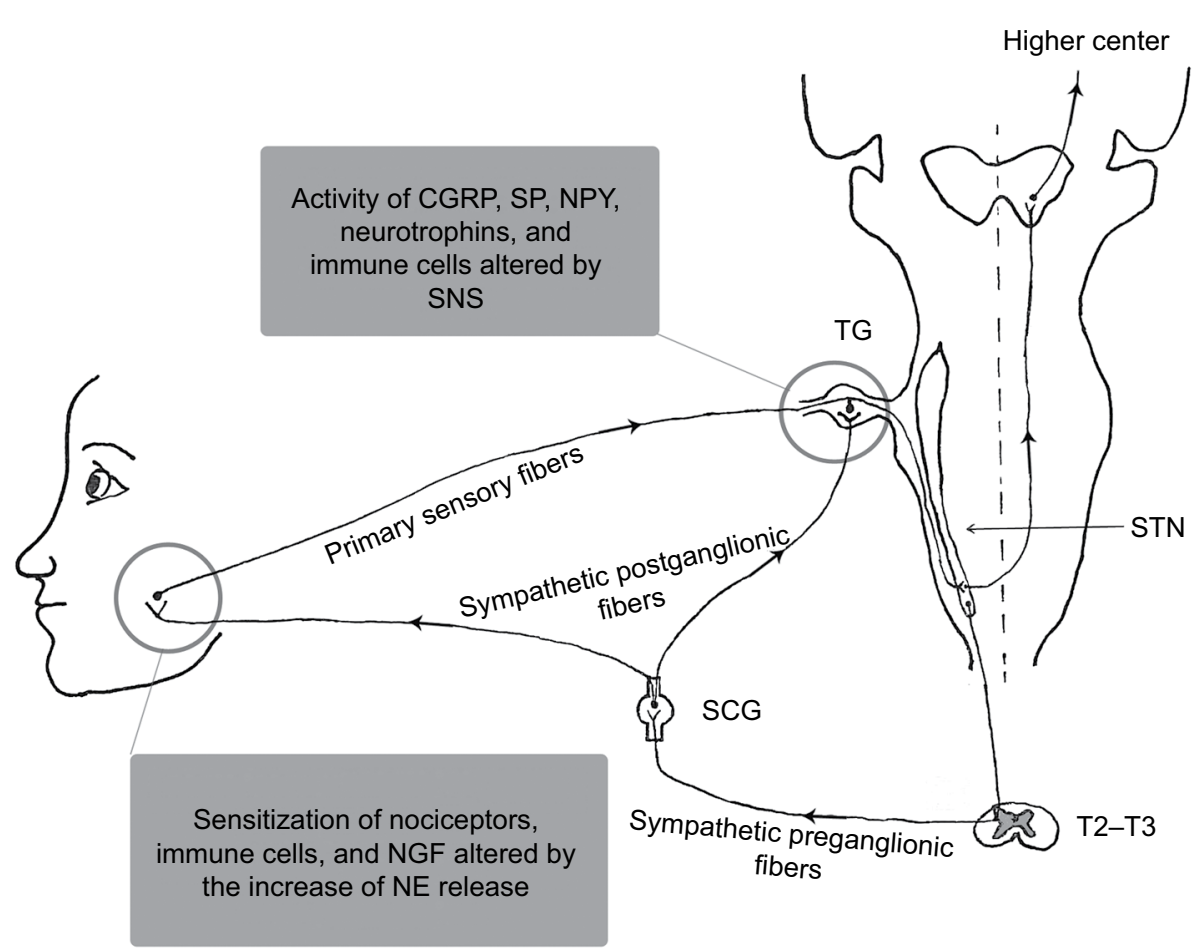

Figure I Schematic diagram of the SNS and possible sympathetic mechanisms in orofacial pain.

Abbreviations: CGRP, calcitonin gene-related peptide; NE, norepinephrine; NGF, nerve growth factor; NPY, neuropeptide Y; SCG, superior cervical sympathetic ganglion; SNS, sympathetic nervous system; SP, substance P; STN, spinal trigeminal nucleus; TG, trigeminal ganglion.

\section{SNS of orofacial region}

The sympathetic innervation of the orofacial region originates in the most rostral intermediolateral horn cells of the spinal cord between segments $\mathrm{T} 2$ and $\mathrm{T} 3$. The axons of preganglionic neurons pass through anterior roots of the spinal cord, ascend in connectives of the sympathetic chain, and synapse with postganglionic neurons in the superior cervical sympathetic ganglion. ${ }^{8}$ The postganglionic axons then distribute to their target organs in the orofacial region (Figure 1). In the neurotransmission of the SNS, preganglionic neurons use acetylcholine as a neurotransmitter, whereas postganglionic neuron nerve fibers release norepinephrine (NE) as a key neurotransmitter. There are five types of adrenergic receptors including $\alpha_{1}, \alpha_{2}, \beta_{1}, \beta_{2}$, and $\beta_{3}$. Of these five subtypes, $\alpha_{2 \mathrm{~A}}$ - and $\alpha_{2 \mathrm{C}}$-adrenoreceptors are expressed in TG of intact animals. ${ }^{9}$ In fact, the neural transmission in the SNS involves the release of multiple neuroactive agents such as neuropeptide Y (NPY), calcitonin gene-related peptide (CGRP), and nitric oxide. ${ }^{10,11}$

\section{Involvement of SNS in orofacial pain}

Morphological study shows that primary sensory and sympathetic fibers innervate the temporomandibular joint (TMJ), which suggests that sympathetic nerves could be responsible for allodynia or neuropathic pain caused by TMJ disorders. ${ }^{12}$ Injury of the mental nerve, a branch of the trigeminal nerve, has been shown to result in sympathetic fiber sprouting in the upper dermis of lower lip skin, an area from which they normally are absent, and form close associations with sensory fibers. ${ }^{11,13-15}$ It suggests that some active molecules released by these ectopic sympathetic fibers may sensitize nociceptive nerve endings, contributing to orofacial pain. Clinically, pain dependent on activity in the SNS is known as sympathetically maintained pain (SMP), which in particular is noted in many cases of complex regional pain syndrome (CRPS, reflex sympathetic dystrophy, causalgia). In SMP, procedures that interrupt the function of the SNS can relieve the pain and hyperalgesia. ${ }^{8}$ In studies of traumatic neuralgias in the maxillofacial region, microsurgical exploration of injured trigeminal nerves in patients with neuralgia reveals that a sprouting of nerve collaterals from adjacent uninjured nerve could be responsible for SMP. ${ }^{16}$ In addition, cervical sympathetic electrical stimulation causes excitation or suppression of cold-receptive cells in the trigeminal nucleus caudalis according to stimulation frequency. ${ }^{17}$ Similarly, sympathetic stimulation affects muscle spindle afferent sensitivity to stretch in rabbit jaw closing muscles. ${ }^{18}$ Clini- 
cally, cervical sympathetic block reduces some pain in the orofacial region. ${ }^{19-23}$ The data suggest that SNS is involved in modulating primary afferent neurons in orofacial region.

\section{Possible sympathetic mechanisms in orofacial pain}

Under normal conditions, sympathetic activity results in the release of $\mathrm{NE}$ at the peripheral receptor sites and does not affect primary nociceptive neurons. However, if the primary neurons have been sensitized by neuroplastic changes, NE released by normal activity of the postganglionic sympathetic neurons can excite adrenergic receptors, which continue to excite these altered primary afferents and thus increase nociceptive input. ${ }^{24}$ The exact mechanism of this peripheral pronociceptive effect is not well known. In TMJ inflammatory pain models, local sympathomimetic amines contribute to the inflammatory TMJ hyperalgesia by activating $\beta_{2}$-adrenoceptors, ${ }^{25-27}$ since $\beta_{2}$-adrenoceptor antagonist or the depletion of NE in the sympathetic terminals can reverse this effect. ${ }^{25,26}$ These results suggest that inflammation may sensitize nociceptors to NE and/or increase the release of the sympathetic amines. Furthermore, there is a study showing that $\alpha_{1}$-adrenoceptor upregulation in the dorsal root ganglion (DRG) after spinal nerve ligation may play an important role in the development of adrenergic sensitivity in injured sensory neurons. ${ }^{28}$ Another study shows that after a chronic nerve constriction, DRG becomes a source of abnormal activity modulated by sympathetically released NE acting on $\alpha_{2}$-adrenoceptors in DRG somata. This neuropathic activity may contribute to cutaneous pain and hyperalgesia. ${ }^{29}$ In contrast, an in vitro study shows that activation of $\alpha_{2}$-adrenoreceptors can hyperpolarize TG neurons. The activation may have an inhibitory effect on nociceptive transmission in the trigeminal system. ${ }^{9}$ There is no information about $\alpha$-adrenoceptor mechanism in orofacial pain models in vivo. It is worth to explore that which subtype of adrenoceptor in the periphery contributes to antinociception and which one to pronociception.

There is considerable evidence showing that the immune system plays an important role in pathophysiological pain conditions. ${ }^{30}$ Haug et al's study shows that unilateral sympathectomy induces a significant increase in immune cell density both in the inflamed and in the uninflamed dental pulp bilaterally. The change of immune cells may induce inflammation and pain in teeth. ${ }^{31}$ Furthermore, immune cells express several types of adrenoceptors. ${ }^{32} \mathrm{Via}$ these adrenergic receptors, NE is able to regulate the level of immune cell activity, which often involves a change in the level of gene expression for cytokines and antibodies. ${ }^{33}$ For example, among the cytokines produced by macrophages, the production and release of the inflammatory cytokine tumor necrosis factor- $\alpha$ is the primary cytokine that is regulated by the SNS. ${ }^{33}$ Interestingly, TMJ inflammation induced by complete Freund's adjuvant activates resident macrophages in the $\mathrm{TG},{ }^{34}$ but the authors did not detect whether SNS is involved in the mechanical allodynia of inflamed TMJ. Cytokines are now recognized as important mediators of inflammatory and neuropathic pain at the level of both nociceptor and neuronal cell bodies of sensory ganglion. ${ }^{35-37}$ No data are obtained concerning how the peripheral NE acts on immune cells and then involves in orofacial pain, which needs to be investigated further.

Most nociceptive primary afferents are unmyelinated (C fibers) and subdivided into peptidergic and nonpeptidergic fibers. There is some evidence that neuropeptides have been implicated in the modulation and transmission of nociceptive input. Substance P (SP), CGRP, and NPY are thought to be important in nociceptive transmission. ${ }^{38-40}$ The ectopic innervation of the upper dermis by sympathetic fibers occurs with SP fiber reinnervation following mental nerve injury. ${ }^{13}$ It suggests that sympathetic-sensory interactions may be involved in the genesis of neuropathic pain. Under normal conditions, NPY resides in sympathetic postganglionic neurons but is absent from the cell bodies of sensory neurons. There are studies showing that NPY is upregulated in the TG neurons after chronic constriction injury of the mental nerve ${ }^{11}$ or inferior alveolar nerve injury. ${ }^{41}$ The upregulation in the neurons may come from sprouted sympathetic fibers or production of TG neurons, which might alter nociceptive transmission of primary afferent fibers. Capsaicin can activate transient receptor potential vanilloid type 1 (TRPV1, a ligand-gated ion channel) that mediates activation of the sensory neurons. Capsaicin increases the release of CGRP from dental pulp biopsies in a concentration-dependent manner, which provides a novel tool to determine the effects of pharmacological compounds on human nociceptor sensitivity. ${ }^{42}$ Hargreaves et al's study demonstrates that NE inhibits capsaicin-evoked CGRP release in dental pulp, and the application of $a$-adrenergic antagonist increases spontaneous release of CGRP. Since capsaicin-sensitive neurons are nociceptors, the result suggests that certain sympathetic neurotransmission may modulate pain. ${ }^{43}$ In addition, CGRP and SP increase significantly in the rat primary trigeminal sensory neurons after sympathectomy. ${ }^{31,44,45}$ The rise of CGRP and SP closely matches the process of the postsympathectomy pain observed clinically. ${ }^{46}$ These findings lead 
to the possibility that sympathetic terminals may modulate sensory peptidergic innervations and activity and then influence nociceptive processing, although in an in vitro study, NE influenced neither the basal release of CGRP nor the stimulated release of CGRP from the dura mater. ${ }^{47}$ In the CNS, CGRP stimulates selectively noradrenergic sympathetic outflow. ${ }^{48}$ In the periphery, whether CGRP increases the release of NE and plays a role in orofacial pain remain to be determined.

Neurotrophins (NTs) such as nerve growth factor (NGF), NT-3, and brain-derived neurotrophic factor are required for the growth and survival of specific populations of sensory and sympathetic neurons. ${ }^{49}$ There is increasing evidence that NTs are peripheral pain mediators and involved in different pain states. ${ }^{50}$ In the periphery, NGF and NT-3 are produced by target tissues, internalized by the innervating sympathetic and/or sensory neuron and retrogradely transported to the cell body. ${ }^{51}$ At the same time, sympathetic input regulates NGF and NT-3 protein expression in peripheral targets. ${ }^{52}$ Following nerve injury, satellite glial cells (glial cells surrounding each sensory neuron in the sensory ganglia) upregulate the synthesis of NTs acting both as promoters of sympathetic sprouting within the ganglion ${ }^{53}$ and as direct sensitizers of nociceptive neurons. ${ }^{54}$ Spinal nerve injury in rat induces a widespread sympathetic nerve outgrowth in affected DRGs. ${ }^{55,56}$ However, several studies have shown that there is no sympathetic sprouting in the rat TG following trigeminal nerve injury. ${ }^{57,58}$ Overexpressing NGF in TG, new sympathetic axons extend into the $\mathrm{TG}$ of transgenic mice and form perineuronal plexuses surrounding only those neurons immunostained for NGF. ${ }^{59}$ Intracerebroventricular infusion of NGF increases sympathetic ingrowth to the TG. ${ }^{60,61}$ The data indicate that it is possible that there is no enough NGF in TG to induce sympathetic sprouting following trigeminal nerve injury. Overexpression of NGF and NT-3 in the skin induces novel sympathetic projections to primary sensory endings. ${ }^{62,63}$ The enhancement of innervation may be regulated by both the low affinity (p75) and/ or high affinity (trkA) NGF receptors in sympathetic and sensory neurons. ${ }^{62-67}$ The increased NGF expression plays a

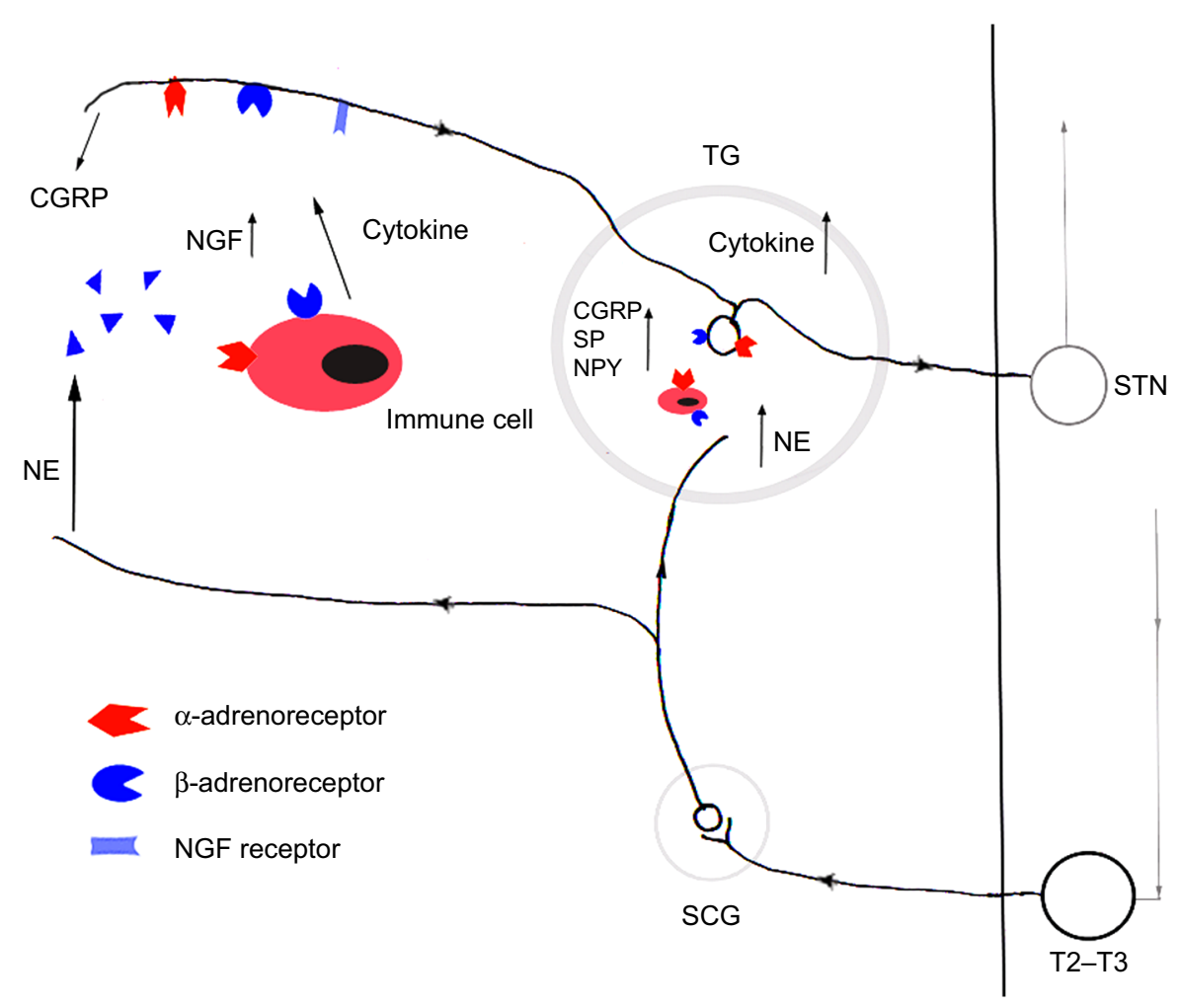

Figure 2 The peripheral molecular mechanisms of SNS in orofacial pain.

Notes: After inflammation and/or nerve injury, adrenoceptors are sensitized. NE released by the normal activity of the sympathetic neurons can excite adrenergic receptors of afferent neurons and immune cell, which can alter some neuroactive molecule expression in neurons and peripheral tissues, and subsequently activates and sensitizes peripheral nociceptors further.

Abbreviations: CGRP, calcitonin gene-related peptide; NE, norepinephrine; NGF, nerve growth factor; NPY, neuropeptide Y; SCG, superior cervical sympathetic ganglion; SNS, sympathetic nervous system; SP, substance P; STN, spinal trigeminal nucleus; TG, trigeminal ganglion. 
role in the development of sympathetic hyperalgesia, ${ }^{63,68,69}$ although sympathectomy does not affect the early ectopic discharge from myelinated fibers in inferior alveolar nerve neuromas. ${ }^{70}$ These results indicate that NGF may play a role in mediating the interactions between sympathetic nerve fiber and nociceptive fibers in orofacial pain. The role might be at the nociceptor level not neuronal soma, but the detailed mechanisms remain to be explored.

\section{Conclusion}

Although the sensory nerves and SNS are generally regarded as discrete structures, the interaction between the SNS and sensory nerves has been associated with orofacial pain (Figures 1 and 2). SNS is involved in many but not all cases of CRPS in orofacial region. The precise mechanisms of SNS in orofacial nociception so far have not been clear, especially in atypical facial pain, stomatodynia, atypical odontalgia, and some forms of masticatory muscle and TMJ disorders. Most investigators focus on the pain mechanisms of SNS in spinal nerve system. However, much less is known about the sympathetic mechanisms in orofacial pain (trigeminal nervous system). The findings about the role of SNS obtained in the DRG could also be operative in the TG, which would be worthy to be confirmed, although the pathophysiology of the trigeminal nerve is in many ways different to that found in spinal nerves. ${ }^{71,72} \mathrm{~A}$ better understanding of SNS and the mechanisms of sympatheticsensory interactions could help us to treat orofacial pain more successfully in the future.

\section{Acknowledgments}

This work was supported partly by the National Natural Science Foundation of China (nos. 81771098, 81470760, and 81541153), Guangdong Provincial Research Project of Science and Technology (no. 2016A050503046), Science and Technology Research Project in Dongguan City (no. 2014108101048), and the Public Service Platform of South China Sea for R\&D Marine Biomedicine Resources (no. 2HC18008).

\section{Disclosure}

The authors report no conflicts of interest in this work.

\section{References}

1. Susan Standring P. Gray's Anatomy. 40th ed. London: Elsevier Limited; 2008:467-468.

2. Okeson JP. Orofacial Pain-Guidelines for Assessment, Diagnosis, and Management. Chicago: Quintessence Books; 1996:10-14.

3. Marani E, Usunoff KG. The trigeminal motonucleus in man. Arch Physiol Biochem. 1998;106(5):346-354.
4. Lazarov NE. Comparative analysis of the chemical neuroanatomy of the mammalian trigeminal ganglion and mesencephalic trigeminal nucleus. Prog Neurobiol. 2002;66(1):19-59.

5. Cortelli P, Pierangeli G. Chronic pain-autonomic interactions. Neurol Sci. 2003;24(Suppl 2):S68-S70.

6. Benarroch EE. Pain-autonomic interactions. Neurol Sci. 2006;27(Suppl 2):s130-s133.

7. Schlereth T, Birklein F. The sympathetic nervous system and pain. Neuromolecular Med. 2008;10(3):141-147.

8. Okeson JP. Bell's Oral and Facial Pain. 7th ed. Chicago: Quintessence Publishing Co, Inc; 2014:73.

9. Takeda M, Ikeda M, Tanimoto T, Lipski J, Matsumoto S. Changes of the excitability of rat trigeminal root ganglion neurons evoked by alpha(2)adrenoreceptors. Neuroscience. 2002;115(3):731-741.

10. Dun NJ, Dun SL, Wu SY, Förstermann U. Nitric oxide synthase immunoreactivity in rat superior cervical ganglia and adrenal glands. Neurosci Lett. 1993;158(1):51-54.

11. Magnussen C, Hung SP, Ribeiro-da-Silva A. Novel expression pattern of neuropeptide $\mathrm{Y}$ immunoreactivity in the peripheral nervous system in a rat model of neuropathic pain. Mol Pain. 2015;11:31.

12. Yoshino K, Kawagishi S, Amano N. Morphological characteristics of primary sensory and post-synaptic sympathetic neurones supplying the temporomandibular joint in the cat. Arch Oral Biol. 1998;43(9):679-686.

13. Ruocco I, Cuello AC, Ribeiro-da-Silva A. Peripheral nerve injury leads to the establishment of a novel pattern of sympathetic fibre innervation in the rat skin. J Comp Neurol. 2000;422(2):287-296.

14. Grelik C, Bennett GJ, Ribeiro-da-Silva A. Autonomic fibre sprouting and changes in nociceptive sensory innervation in the rat lower lip skin following chronic constriction injury. Eur J Neurosci. 2005;21(9):2475-2487.

15. Taylor AM, Osikowicz M, Ribeiro-da-Silva A. Consequences of the ablation of nonpeptidergic afferents in an animal model of trigeminal neuropathic pain. Pain. 2012;153(6):1311-1319.

16. Gregg JM. Studies of traumatic neuralgias in the maxillofacial region: surgical pathology and neural mechanisms. J Oral Maxillofac Surg. 1990;48(3):228-237.

17. Davies SN. Sympathetic modulation of cold-receptive neurones in the trigeminal system of the rat. J Physiol. 1985;366:315-329.

18. Roatta S, Windhorst U, Ljubisavljevic M, Johansson H, Passatore M. Sympathetic modulation of muscle spindle afferent sensitivity to stretch in rabbit jaw closing muscles. J Physiol. 2002;540(Pt 1):237-248.

19. Noma N, Kamo H, Nakaya Y, et al. Stellate ganglion block as an early intervention in sympathetically maintained headache and orofacial pain caused by temporal arteritis. Pain Med. 2013;14(3):392-397.

20. Kohjitani A, Miyawaki T, Kasuya K, Shimada M. Sympathetic activitymediated neuropathic facial pain following simple tooth extraction: a case report. Cranio. 2002;20(2):135-138.

21. Lynch ME, Elgeneidy AK. The role of sympathetic activity in neuropathic orofacial pain. J Orofac Pain. 1996;10(4):297-305.

22. Sakamoto E, Shiiba S, Noma N, et al. A possible case of complex regional pain syndrome in the orofacial region. Pain Med. 2010;11(2):274-280.

23. O'Connell NE, Wand BM, Gibson W, Carr DB, Birklein F, Stanton TR. Local anaesthetic sympathetic blockade for complex regional pain syndrome. Cochrane Database Syst Rev. 2016;7:CD004598.

24. Stephen McMahon. Wall and Melzack's Textbook of Pain. 6th ed. Philadelphia: Elsevier Ltd; 2013:49-50.

25. Chichorro JG, Lorenzetti BB, Zampronio AR. Involvement of bradykinin, cytokines, sympathetic amines and prostaglandins in formalin-induced orofacial nociception in rats. Br J Pharmacol. 2004;141(7):1175-1184.

26. Oliveira-Fusaro MC, Clemente-Napimoga JT, Teixeira JM, TorresChávez KE, Parada CA, Tambeli CH. 5-HT induces temporomandibular joint nociception in rats through the local release of inflammatory mediators and activation of local $\beta$ adrenoceptors. Pharmacol Biochem Behav. 2012;102(3):458-464. 
27. Rodrigues LL, Oliveira MC, Pelegrini-da-Silva A, de Arruda Veiga $\mathrm{MC}$, Parada CA, Tambeli $\mathrm{CH}$. Peripheral sympathetic component of the temporomandibular joint inflammatory pain in rats. $J$ Pain. 2006;7(12):929-936.

28. Xie J, Ho Lee Y, Wang C, Mo Chung J, Chung K. Differential expression of alpha1-adrenoceptor subtype mRNAs in the dorsal root ganglion after spinal nerve ligation. Brain Res Mol Brain Res. 2001;93(2):164-172.

29. Xie Y, Zhang J, Petersen M, Lamotte RH. Functional changes in dorsal root ganglion cells after chronic nerve constriction in the rat. $J$ Neurophysiol. 1995;73(5):1811-1820.

30. Moalem G, Tracey DJ. Immune and inflammatory mechanisms in neuropathic pain. Brain Res Rev. 2006;51(2):240-264.

31. Haug SR, Berggreen E, Heyeraas KJ. The effect of unilateral sympathectomy and cavity preparation on peptidergic nerves and immune cells in rat dental pulp. Exp Neurol. 2001;169(1):182-190.

32. Binder W, Mousa SA, Sitte N, Kaiser M, Stein C, Schäfer M. Sympathetic activation triggers endogenous opioid release and analgesia within peripheral inflamed tissue. Eur J Neurosci. 2004;20(1):92-100.

33. Nance DM, Sanders VM. Autonomic innervation and regulation of the immune system (1987-2007). Brain Behav Immun. 2007;21(6):736-745.

34. Villa G, Ceruti S, Zanardelli M, et al. Temporomandibular joint inflammation activates glial and immune cells in both the trigeminal ganglia and in the spinal trigeminal nucleus. Mol Pain. 2010;6:89.

35. Cook AD, Christensen AD, Tewari D, Mcmahon SB, Hamilton JA. Immune Cytokines and Their Receptors in Inflammatory Pain. Trends Immunol. 2018;39(3):240-255.

36. Al-Mazidi S, Alotaibi M, Nedjadi T, Chaudhary A, Alzoghaibi M, Djouhri L. Blocking of cytokines signalling attenuates evoked and spontaneous neuropathic pain behaviours in the paclitaxel rat model of chemotherapy-induced neuropathy. Eur J Pain. 2018;22(4):810-821.

37. Capossela S, Pavlicek D, Bertolo A, Landmann G, Stoyanov JV. Unexpectedly decreased plasma cytokines in patients with chronic back pain. J Pain Res. 2018;11:1191-1198.

38. Elcock C, Boissonade FM, Robinson PP. Changes in neuropeptide expression in the trigeminal ganglion following inferior alveolar nerve section in the ferret. Neuroscience. 2001;102(3):655-667.

39. Skofitsch G, Jacobowitz DM. Calcitonin gene-related peptide coexists with substance $\mathrm{P}$ in capsaicin sensitive neurons and sensory ganglia of the rat. Peptides. 1985;6(4):747-754.

40. Takano S, Uchida K, Inoue G, et al. Increase and regulation of synovial calcitonin gene-related peptide expression in patients with painful knee osteoarthritis. J Pain Res. 2017;10:1099-1104.

41. Fristad I, Heyeraas KJ, Kvinnsland IH. Neuropeptide Y expression in the trigeminal ganglion and mandibular division of the trigeminal nerve after inferior alveolar nerve axotomy in young rats. Exp Neurol. 1996;142(2):276-286

42. Fehrenbacher JC, Sun XX, Locke EE, Henry MA, Hargreaves KM. Capsaicin-evoked iCGRP release from human dental pulp: a model system for the study of peripheral neuropeptide secretion in normal healthy tissue. Pain. 2009;144(3):253-261.

43. Hargreaves KM, Bowles WR, Jackson DL. Intrinsic regulation of CGRP release by dental pulp sympathetic fibers. $J$ Dent Res. 2003;82(5):398-401.

44. Schon F, Ghatei M, Allen JM, Mulderry PK, Kelly JS, Bloom SR. The effect of sympathectomy on calcitonin gene-related peptide levels in the rat trigeminovascular system. Brain Res. 1985;348(1):197-200.

45. Kessler JA, Bell WO, Black IB. Substance P levels differ in sympathetic target organ terminals and ganglion perikarya. Brain Res. 1983;258(1):144-146.

46. Schon F. Postsympathectomy pain and changes in sensory neuropeptides: towards an animal model. Lancet. 1985;2(8465):1158-1160.

47. Ebersberger A, Takac H, Richter F, Schaible HG. Effect of sympathetic and parasympathetic mediators on the release of calcitonin gene-related peptide and prostaglandin E from rat dura mater, in vitro. Cephalalgia. 2006;26(3):282-289.
48. Fisher LA, Kikkawa DO, Rivier JE, et al. Stimulation of noradrenergic sympathetic outflow by calcitonin gene-related peptide. Nature. 1983;305(5934):534-536.

49. Ceni C, Unsain N, Zeinieh MP, Barker PA. Neurotrophins in the regulation of cellular survival and death. Handb Exp Pharmacol. 2014;220:193-221.

50. Khan N, Smith MT. Neurotrophins and Neuropathic Pain: Role in Pathobiology. Molecules. 2015;20(6):10657-10688.

51. Kuruvilla R, Zweifel LS, Glebova NO, et al. A neurotrophin signaling cascade coordinates sympathetic neuron development through differential control of TrkA trafficking and retrograde signaling. Cell. 2004;118(2):243-255.

52. Randolph CL, Bierl MA, Isaacson LG. Regulation of NGF and NT-3 protein expression in peripheral targets by sympathetic input. Brain Res. 2007;1144:59-69.

53. Pertin M, Allchorne AJ, Beggah AT, Woolf CJ, Decosterd I. Delayed sympathetic dependence in the spared nerve injury (SNI) model of neuropathic pain. Mol Pain. 2007;3:21.

54. Wu JR, Chen H, Yao YY, et al. Local injection to sciatic nerve of dexmedetomidine reduces pain behaviors, SGCs activation, NGF expression and sympathetic sprouting in CCI rats. Brain Res Bull. 2017;132:118-128.

55. Chung K, Lee BH, Yoon YW, Chung JM. Sympathetic sprouting in the dorsal root ganglia of the injured peripheral nerve in a rat neuropathic pain model. J Comp Neurol. 1996;376(2):241-252.

56. Lee BH, Yoon YW, Chung K, Chung JM. Comparison of sympathetic sprouting in sensory ganglia in three animal models of neuropathic pain. Exp Brain Res. 1998;120(4):432-438.

57. Bongenhielm U, Boissonade FM, Westermark A, Robinson PP, Fried K. Sympathetic nerve sprouting fails to occur in the trigeminal ganglion after peripheral nerve injury in the rat. Pain. 1999;82(3):283-288.

58. Benoliel R, Eliav E, Tal M. No sympathetic nerve sprouting in rat trigeminal ganglion following painful and non-painful infraorbital nerve neuropathy. Neurosci Lett. 2001;297(3):151-154.

59. Walsh GS, Kawaja MD. Sympathetic axons surround nerve growth factor-immunoreactive trigeminal neurons: observations in mice overexpressing nerve growth factor. J Neurobiol. 1998;34(4):347-360.

60. Shoemaker SE, Kudwa AE, Isaacson LG. Sympathetic ingrowth to the trigeminal ganglion following intracerebroventricular infusion of nerve growth factor. Brain Res. 2002;956(1):136-148.

61. Nauta HJ, Wehman JC, Koliatsos VE, Terrell MA, Chung K. Intraventricular infusion of nerve growth factor as the cause of sympathetic fiber sprouting in sensory ganglia. J Neurosurg. 1999;91(3):447-453.

62. Davis BM, Goodness TP, Soria A, Albers KM. Over-expression of NGF in skin causes formation of novel sympathetic projections to trkA-positive sensory neurons. Neuroreport. 1998;9(6):1103-1107.

63. Albers KM, Perrone TN, Goodness TP, Jones ME, Green MA, Davis BM. Cutaneous overexpression of NT-3 increases sensory and sympathetic neuron number and enhances touch dome and hair follicle innervation. J Cell Biol. 1996;134(2):487-497.

64. Smeyne RJ, Klein R, Schnapp A, et al. Severe sensory and sympathetic neuropathies in mice carrying a disrupted Trk/NGF receptor gene. Nature. 1994;368(6468):246-249.

65. Zhou XF, Rush RA. Endogenous nerve growth factor is required for regulation of the low affinity neurotrophin receptor (p75) in sympathetic but not sensory ganglia. J Comp Neurol. 1996;372(1):37-48.

66. Walsh GS, Krol KM, Kawaja MD. Absence of the p75 neurotrophin receptor alters the pattern of sympathosensory sprouting in the trigeminal ganglia of mice overexpressing nerve growth factor. $J$ Neurosci. 1999;19(1):258-273.

67. Dhanoa NK, Krol KM, Jahed A, Crutcher KA, Kawaja MD. Null mutations for exon III and exon IV of the p75 neurotrophin receptor gene enhance sympathetic sprouting in response to elevated levels of nerve growth factor in transgenic mice. Exp Neurol. 2006;198(2):416-426.

68. Davis BM, Albers KM, Seroogy KB, Katz DM. Overexpression of nerve growth factor in transgenic mice induces novel sympathetic projections to primary sensory neurons. J Comp Neurol. 1994;349(3):464-474. 
69. Anderson LC, Rao RD. Interleukin-6 and nerve growth factor levels in peripheral nerve and brainstem after trigeminal nerve injury in the rat. Arch Oral Biol. 2001;46(7):633-640.

70. Bongenhielm U, Yates JM, Fried K, Robinson PP. Sympathectomy does not affect the early ectopic discharge from myelinated fibres in ferret inferior alveolar nerve neuromas. Neurosci Lett. 1998;245(2):89-92.
71. Latrémolière A, Mauborgne A, Masson J, et al. Differential implication of proinflammatory cytokine interleukin- 6 in the development of cephalic versus extracephalic neuropathic pain in rats. $J$ Neurosci. 2008;28(34):8489-8501.

72. Fried K, Bongenhielm U, Boissonade FM, Robinson PP. Nerve injury-induced pain in the trigeminal system. Neuroscientist. 2001;7(2):155-165.

\section{Publish your work in this journal}

The Journal of Pain Research is an international, peer reviewed, open access, online journal that welcomes laboratory and clinical findings in the fields of pain research and the prevention and management of pain. Original research, reviews, symposium reports, hypothesis formation and commentaries are all considered for publication.

\section{Dovepress}

The manuscript management system is completely online and includes a very quick and fair peer-review system, which is all easy to use. Visit http://www.dovepress.com/testimonials.php to read real quotes from published authors. 